\title{
Valor nutritivo da silagem de maniçoba (Manihot pseudoglaziovii) com e sem fubá de milho como aditivo
}

\author{
Nutritional value of maniçoba ("Manihot pseudoglaziovii”) silage with and without \\ corn meal as additive
}

\author{
BACKES, Alfredo Acosta ${ }^{1 *}$; SANTOS, Laelson Lima dos ${ }^{2}$; FAGUNDES, Jailson \\ Lara $^{1}$; BARBOSA, Leandro Teixeira ${ }^{1}$; MOTA, Marcelo ${ }^{2}$; VIEIRA, Jodnes Sobreira ${ }^{1}$
}

\author{
${ }^{1}$ Universidade Federal de Sergipe, Departamento de Zootecnia, São Cristóvão, Sergipe, Brasil. \\ ${ }^{2}$ Universidade Federal de Sergipe, Programa de Pós-Graduação em Agroecossistema, São Cristóvão, \\ Sergipe, Brasil \\ *Endereço para correspondência: alfredoaab_67@yahoo.com.br
}

\section{RESUMO}

O estudo foi conduzido com o objetivo de estudar o valor nutritivo da Maniçoba sob a forma de silagem, com ou sem fubá de milho como aditivo. Os tratamentos utilizados foram: silagem de maniçoba (SM) com quatro níveis $(0 ; 10 ; 20$ e $30 \%)$ de adição de fubá de milho como aditivo, sendo cinco repetições por tratamento. $\mathrm{O}$ pH das silagens se manteve entre 4,1 e 4,3 tanto para silagens com e sem aditivo, indicando que ocorreu uma boa fermentação láctica independente da adição de fubá de milho. Para DIVMS ocorreram valores crescentes e significativos $(\mathrm{P}<0,05)$ à medida que houve aumento da adição de fubá de milho, sendo que a inclusão de $20 \%$ de fubá foi responsável pelo maior valor deste parâmetro $(65,1 \%)$. As concentrações de ácido acético e butírico foram reduzidas na medida em que foram adicionados níveis crescentes de aditivo. As concentrações de ácido láctico foram consideradas satisfatórias em todos os tratamentos. Ocorreu decréscimo significativo $(\mathrm{p}<0,05)$ nos teores de FDN e FDA com a inclusão do fubá de milho, sendo encontrado o menor valor para o tratamento com $20 \%$ de aditivo. Conclui-se que a silagem de maniçoba é uma alternativa alimentar de bom valor nutricional, principalmente quando adicionado de fubá de milho como aditivo. O melhor nível de inclusão de fubá de milho na silagem da maniçoba é de $20 \%$.

Palavras-chave: ácido láctico, digestibilidade, fibra, forrageira, proteína

\section{SUMMARY}

With the objective to study the nutritional value of maniçoba in silage form, with or without corn meal, this study was undertaken. The used treatments were: maniçoba silage with four levels $(0 ; 10 ; 20$ and 30$)$ of addition of corn meal, with five repetitions for treatment. The $\mathrm{pH}$ of the silage remained between 4.1 to 4.3 which would be satisfactory indicating that there was a good lactic fermentation, independent in the addition of corn meal. For DIVMS occurred significant increase values ( $P$ $\leq 0.05$ ) due to the increment in the addition of corn meal, and the inclusion of $20 \%$ corn proved to be capable of providing highest value of this parameter $(65.1 \%)$. The acetic and butyric acids concentrations were reduced in the measure in that growing levels were added of additives. The lactic acid concentrations were considered satisfactory in all of the treatments. There was a significant decrease $(\mathrm{p}<0.05)$ in NDF and ADF with the inclusion of corn meal. However the lowest value for traits was observed in treatment with $20 \%$ addictive. It is concluded that maniçoba silage is an alternative source of good nutritional value, especially when added to corn meal as additive. The better level of inclusion of corn meal in maniçoba silage is $20 \%$.

Keywords: digestibility, fiber, forage, lactic acid, protein 


\section{INTRODUÇ̃̃̃O}

A pecuária no semi-árido é importante para o produtor da região, entretanto essa atividade não é fácil de ser conduzido devido as chuvas se concentrarem em um período de três a quatro meses. Segundo Costa et al. (2008) os produtores rurais do semiárido utilizam a pastagem nativa como uma das principais fontes de alimentação dos rebanhos, no entanto, nos períodos estiagem, a capacidade de suporte da caatinga é limitada e ocasiona baixos índices produtivos por não atender às exigências mínimas dos animais. Portanto, a produção de alimentos para ruminantes constitui-se no maior desafio enfrentado pelos criadores para viabilizar a atividade pecuária nessa região.

Para tornar a exploração pecuária economicamente viável, sustentável e possível em regiões semi-áridas, várias pesquisas têm sido desenvolvidas com alimentos alternativos, combinações entre alimentos e formas de conservação (SILVA et al, 2007; COSTA et al, 2008; ARAÚJO et al, 2009). A utilização de forrageiras nativas pode ser uma estratégia viável desde que se tenha conhecimento dos seus aspectos agronômicos, nutricionais, efeitos de sua adição nas dietas e respostas sobre a produtividade dos rebanhos.

Dentre a grande diversidade da flora da caatinga nordestina a maniçoba (Manihot pseudoglaziovvi) apresenta-se bastante disseminada e abundante por toda região. Possui bom valor nutritivo, principalmente em proteína e pode representar uma alternativa natural para disponibilizar alimentos conservados nos períodos de carência nutricional do rebanho. No trabalho realizado por Costa et al. (2008), com silagem de maniçoba, foram encontrados valores de proteína de $15,3 \%$ e no trabalho de Medina et al. (2009) um teor maior de $20,4 \%$, mostrando o excelente valor protéico dessa forragem.

O fubá milho (Zea mays) é o ingrediente mais utilizado como alimento energético. $\mathrm{O}$ elevado teor de energia do fubá deve-se ao fato de grão de milho apresentar níveis elevados de amido e bom teor de açúcares. $\mathrm{Na}$ ensilagem, a adição do fubá de milho, além de aumentar os teores de matéria seca e de açúcares, promove uma melhora no processo de fermentação láctica. Portanto, através do presente trabalho objetivou-se determinar o valor nutritivo da silagem da maniçoba (Manihot pseudoglaziovii), com e sem fubá de milho como aditivo, a fim de estudar a viabilidade dessa forrageira lenhosa para o produtor, como forma alternativa de manter a pecuária sustentável no semi-árido.

\section{MATERIAL E MÉTODOS}

O estudo foi realizado nas dependências do Departamento de Zootecnia da Universidade Federal de Sergipe, localizada no município de São Cristóvão, Sergipe. Os tratamentos utilizados foram: silagem de maniçoba (SM) com quatro níveis $(0 ; 10 ; 20$ e 30\%) de adição de fubá de milho como aditivo, sendo cinco repetições por tratamento.

A forrageira usada, para a composição das silagens foi coletada no município de Santana do Ipanema Estado de Alagoas, localizado na micro-região do sertão, situada a 250 metros acima do nível do mar, com temperaturas médias anuais de $20^{\circ}$ a $39^{\circ} \mathrm{C}$ e pluviosidade média anual de $650 \mathrm{~mm}$. Foi realizado o corte dos ramos da maniçoba (folhas + hastes) de diâmetro de um lápis aproximadamente. Após, o material foi 
triturado em máquina forrageira, deixando as partículas medindo aproximadamente $2,0 \mathrm{~cm}$, posteriormente a forragem foi distribuída em quatro partes e o fubá de milho misturado nas proporções de $0 ; 10 ; 20$ e $30 \%$, respectivamente, em função da matéria seca. No momento da mistura, foi obtida amostras da maniçoba para a determinação do seu poder tampão (PT) (PLAYNE \& McDONALD, 1966). Feita as misturas essas foram colocadas em tubos de PVC (mini-silos) de $150 \mathrm{~mm}$ de diâmetro e $50 \mathrm{~cm}$ de profundidade, forrado internamente com saco de plástico, compactado e vedado. Estes mini-silos foram cobertos com terra permanecendo assim durante um período de aproximadamente 60 dias, tempo suficiente para ocorrer à fermentação láctica e, por conseqüência, transformação em silagem.

No momento da abertura dos mini-silos foram obtidas amostras das silagens de cada repetição dos tratamentos, sendo acondicionadas em saco plásticos, etiquetadas e enviadas para o laboratório, para a realização das seguintes análises químico-bromatológicas: matéria seca (MS), matéria orgânica (MO), extrato etéreo $(\mathrm{EE})$, cinzas $(\mathrm{CZ})$, proteína bruta (PB), proteína insolúvel em detergente neutra (PIDN), proteína insolúvel em detergente ácido (PIDA), fibra em detergente neutro (FDN), fibra em detergente ácido (FDA), lignina (LIG), celulose (CEL) e hemicelulose (HEM), potencial hidrogeniônico $(\mathrm{pH})$, ácido láctico (AC. LACT), nitrogênio amoniacal $\left(\mathrm{N}-\mathrm{NH}_{3} / \mathrm{NT}\right)$ e digestibilidade "in vitro" da matéria seca (DIVMS) (Silva \& Queiroz, 2002). Os Carboidratos totais (CHOT) foram estimados conforme equação proposta por Sniffen et al. (1992), $\mathrm{CHOT}=100-(\% \mathrm{~PB}+\% \mathrm{EE}+$
$\% \mathrm{CZ}$ ) e os nutrientes digestíveis totais (NDT) foram estimados conforme equação de regressão proposta por Capelle et al. (2001), cuja equação é: NDT $=83,79-0,4171$ FDN. Carboidratos não fibrosos (CNF) foi estimado pela diferença entre carboidratos totais (CHOT) e fibra em detergente neutra $(\mathrm{FDN})(\mathrm{CNF}=\mathrm{CHOT}$ - FDN).

Os ácidos orgânicos (acético, butírico e propiônico) foram determinados por cromatografia de fase líquida de elevada eficiência (HPLC), conforme metodologia descrita por Mathew et al. (1997), filtrando-se aproximadamente $2 \mathrm{~mL}$ do sobrenadante de cada amostra de suco da silagem em membrana de acetato de celulose com porosidade $0,45 \mu \mathrm{m}$. As características químicobromatológica da forragem (planta fresca) na hora da ensilagem são apresentadas na Tabela 1 .

Tabela 1. Composição nutricional da maniçoba e do fubá de milho utilizado na confecção das silagens

\begin{tabular}{|c|c|c|}
\hline Nutrientes & Maniçoba & $\begin{array}{c}\text { Fubá de } \\
\text { milho }\end{array}$ \\
\hline Matéria seca & 23,4 & 86,7 \\
\hline Matéria orgânica ${ }^{1}$ & 93,6 & 97,35 \\
\hline Extrato etéreo ${ }^{1}$ & 2,06 & 3,7 \\
\hline Cinzas $^{1}$ & 6,4 & 2,65 \\
\hline Proteína bruta $^{1}$ & 15,13 & 7,2 \\
\hline $\begin{array}{l}\text { Fibra em detergente } \\
\text { neutra }^{1}\end{array}$ & 55,71 & 27,5 \\
\hline $\begin{array}{l}\text { Fibra em detergente } \\
\text { ácida }^{1}\end{array}$ & 46,65 & 8,1 \\
\hline Lignina $^{1}$ & 14,12 & 1,1 \\
\hline $\begin{array}{l}\text { Digestibilidade "in } \\
\text { vitro" da matéria seca }\end{array}$ & 41,5 & 68,7 \\
\hline Poder Tampão ${ }^{2}$ & 20,61 & - \\
\hline
\end{tabular}


Para a avaliação dos resultados, foi realizada análise de variância (ANOVA) e quando esta se apresentou significativa, em nível de $5 \%$ de probabilidade, foi feito um teste de comparação de médias denominado teste de Dunnett, utilizando o pacote estatístico SAS (STATISTICAL ANALYSIS SYSTEMS, 2004).

\section{RESULTADOS E DISCUSSÃO}

A maniçoba apresenta um poder tampão $(20,61$ eq. $\mathrm{mg} / 100 \mathrm{~g}$ matéria seca) normal para forrageiras que contenham tanino, porém ainda considerado baixo. O tanino é um composto fenólico existente nesta planta, o qual pode ser responsável por dificultar a queda do $\mathrm{pH}$ da silagem durante o processo de fermentação no silo. Em forragens que não possuem tanino $o$ poder tampão fica, normalmente, abaixo de $20 \mathrm{meq} / 100 \mathrm{~g}$ MS da forragem, isto é, valores abaixo do que foi observado no presente trabalho. Segundo Pinho et al. (2004) o poder tampão da planta a ser ensilada é uma característica que determina o rápido estabelecimento da fermentação láctica no processo de confecção da silagem conferindo, dessa forma, características desejáveis à essa silagem.

A silagem de maniçoba sem aditivo apresentou baixo teor de MS enquanto que para silagem com $10 \%$ de aditivo esse teor apresentou-se dentro dos padrões desejáveis para uma boa silagem que é de 30 a 35\% (Tabela 2). Entretanto, nas silagens com 20 e $30 \%$ de aditivo o teor de MS mostrou-se elevado $(p<0,05)$. Com relação a MO houve aumento significativo $(\mathrm{p}<0,05)$ para os tratamentos com aditivos. Portanto, os valores de MS e MO apresentaram valores crescentes a partir da inclusão do fubá de milho até o percentual de $20 \%$. Esse comportamento já era esperado visto que o valor de MS na composição do fubá de milho é maior que o da maniçoba e o teor de $\mathrm{CZ}$ menor. Essa menor quantidade de minerais do fubá de milho influenciou para que o teor de CZ fosse decrescente com a inclusão desse aditivo. Em seu trabalho Andrade et al. (2012) observaram um aumento significativo no teor de MS com inclusão de $10 \%$ de fubá de milho como aditivo em silagem de capim elefante, fato também observado no presente trabalho, porém com $20 \%$ de fubá de milho.

A inclusão do aditivo proporcionou decréscimo no teor de proteína bruta $(p<0,05)$ da silagem de maniçoba. Isso pode ser explicado pelo fato de que o fubá de milho contém pouca proteína e, portanto, à medida que é aumentada sua inclusão na silagem o nível total de proteína se reduz.

Com a inclusão do fubá de milho como aditivo também ocorreu decréscimo significativo $(p<0,05)$ nos teores de PIDN e PIDA. Isso mostra o efeito significativo e benéfico da adição do fubá de milho, sendo que essas respostas são em virtude de uma melhor fermentação ocorrida durante 0 processo de ensilagem.

Em termos de valores de $\mathrm{N}-\mathrm{NH}_{3} / \mathrm{NT}$ pode-se observar que não houve diferença estatística $(p>0,05)$ entre os tratamentos. Os níveis de $\mathrm{N}-\mathrm{NH}_{3} / \mathrm{NT}$ mantiveram-se dentro de uma faixa adequada os quais são conseqüências de um $\mathrm{pH}$ adequado $(4,2)$ e, portanto, de uma boa fermentação. Segundo Guim et al. (2004), os níveis de $\mathrm{N}-\mathrm{NH}_{3} / \mathrm{NT}$ até $6 \%$ é considerado dentro dos limites aceitáveis. A maior atividade das proteases ocorre com $\mathrm{pH}$ entre 5 a 6 , portanto o baixo $\mathrm{pH}$ evita a proteólise em demasia e por conseqüência mantêm o $\mathrm{N}_{-} \mathrm{NH}_{3} / \mathrm{NT}$ dentro dos limites recomendados. 
Rev. Bras. Saúde Prod. Anim., Salvador, v.15, n.1, p.182-191 jan./mar., 2014 http://www.rbspa.ufba.br ISSN 15199940

Tabela 2. Composição químico-bromatológica e potencial fermentativo das silagens de maniçoba com diferentes níveis de fubá de milho como aditivo

\begin{tabular}{|c|c|c|c|c|c|}
\hline \multirow{2}{*}{ Nutrientes } & \multicolumn{4}{|c|}{ Níveis de aditivo $^{1}$} & \multirow{2}{*}{$\begin{array}{l}\mathrm{CV} \\
(\%)\end{array}$} \\
\hline & 0 & 10 & 20 & 30 & \\
\hline Matéria seca & $29,6^{b}$ & $34,7^{\mathrm{ab}}$ & $40,9^{\mathrm{a}}$ & $40,4^{\mathrm{a}}$ & 10,8 \\
\hline Matéria orgânica ${ }^{1}$ & $92,4^{\mathrm{b}}$ & $93,9^{\mathrm{a}}$ & $94,7^{\mathrm{a}}$ & $94,6^{\mathrm{a}}$ & 0,6 \\
\hline Extrato etéreo $^{1}$ & 3,3 & 3,5 & 3,8 & 3,1 & 18,5 \\
\hline Cinzas $^{1}$ & $7,6^{\mathrm{a}}$ & $6,1^{b}$ & $5,3^{\mathrm{b}}$ & $5,3^{\mathrm{b}}$ & 9,6 \\
\hline Proteína bruta ${ }^{1}$ & $14,4^{\mathrm{a}}$ & $13,6^{\mathrm{b}}$ & $13,7^{\mathrm{b}}$ & $12,6^{\mathrm{b}}$ & 7,5 \\
\hline $\begin{array}{l}\text { Proteína insolúvel em detergente } \\
\text { neutra }^{2}\end{array}$ & $24,2^{\mathrm{a}}$ & $15,9^{\mathrm{b}}$ & $14,1^{\mathrm{b}}$ & $14,9^{\mathrm{b}}$ & 8,5 \\
\hline $\begin{array}{l}\text { Proteína insolúvel em detergente } \\
\text { Ácido }^{2}\end{array}$ & $20,9^{\mathrm{a}}$ & $13,9^{\mathrm{b}}$ & $10,8^{\mathrm{b}}$ & $11,1^{\mathrm{b}}$ & 13,6 \\
\hline Nitrogênio amoniacal ${ }^{3}$ & 3,6 & 3,78 & 3,91 & 3,95 & 9,7 \\
\hline Nutrientes digestíveis totais 1 & $61,9^{\mathrm{c}}$ & $67,0^{\mathrm{b}}$ & $69,9^{\mathrm{a}}$ & $66,9^{\mathrm{b}}$ & 1,3 \\
\hline Potencial hidrogeniônico & 4,1 & 4,2 & 4,3 & 4,2 & 4,7 \\
\hline $\begin{array}{l}\text { Digestibilidade "in vitro" da } \\
\text { matéria seca }\end{array}$ & $42,9^{\mathrm{c}}$ & $53,9^{\mathrm{b}}$ & $65,1^{\mathrm{a}}$ & $60,6^{\mathrm{a}}$ & 5,7 \\
\hline
\end{tabular}

Médias seguidas de letras diferentes na linha diferem pelo teste "Dunnett" a $5 \%$ de probabilidade.

${ }^{1}$ Expresso em percentagem da matéria seca; ${ }^{2}$ Expresso em percentagem da proteína bruta; ${ }^{3}$ Expresso em percentagem do nitrogênio total.

$\mathrm{CV}=$ coeficiente de variação.

A silagem de maniçoba com e sem aditivo de fubá de milho apresentou bons valores de NDT, superior a $60 \%$. $\mathrm{Na}$ silagem sem aditivo observou-se valor de $61,9 \%$ de NDT e quando adicionou-se fubá de milho em até 20 $\%$, esse valor alcançou patamares de $69,9 \%$, valor semelhante ao encontrado por Matos et al. (2005) que foi de 70,5 $\%$ os quais trabalharam com silagem de maniçoba sem aditivo. Ao ser adicionado fubá de milho à silagem de maniçoba houve efeito aditivo para o conteúdo de energia explicando, dessa forma, a elevação do teor de NDT dessa silagem.

Um dos parâmetros para se avaliar a qualidade nutricional de uma forrageira é a sua digestibilidade. Assim, no presente trabalho, ocorreram valores crescentes e significativos $(p<0,05)$ para DIVMS da silagem de maniçoba à medida que houve aumento da adição de fubá de milho, sendo que o maior valor deste parâmetro $(65,1 \%)$ foi com a inclusão de $20 \%$. O fato do fubá de milho apresentar elevada digestibilidade $(68,7 \%)$ aliado ao fato deste aditivo ter proporcionado fermentação láctica adequada contribuíram para que houvesse elevação da DIVMS da silagem. Em seu trabalho Medina et al. (2009), encontraram valores de $39,7 \%$ e de 52,1 $\%$ de DIVMS para silagem de maniçoba sem e com aditivo, respectivamente, valores esses inferiores ao encontrado no presente trabalho.

A qualidade fermentativa das silagens foi considerada satisfatória podendo ser comprovada pelo $\mathrm{pH}$ que se manteve entre 4,1 e 4,3 tanto para silagens com e sem aditivo, indicando que ocorreu uma boa fermentação láctica independente da adição ou não de fubá de milho. Segundo Carvalho et al. (2008), a faixa de $\mathrm{pH}$ considerada ótima é entre 3,8 à 4,2 , isto é, valores esses que estão de acordo com o que foi encontrado no presente trabalho. Matos et al. (2005), trabalhando com silagem de maniçoba sem aditivo, encontraram valores de $\mathrm{pH}$ de 3,9 o que pode ser considerado 
próximo ao encontrado no presente trabalho. Segundo esses mesmos autores a maniçoba apresenta níveis adequados de substâncias fermentáveis, principalmente carboidratos solúveis e baixo poder tampão, para conservação através de ensilagem. Essas características da maniçoba fazem com que ocorra um bom desenvolvimento das bactérias lácticas com rápida queda do $\mathrm{pH}$, contribuindo para que ocorra uma melhor conservação e evitando perdas de nutrientes por atuação de microrganismos indesejáveis, tais como clostridium (principal responsável pela fermentação butírica) e leveduras/coliformes (fermentação acética).

Os valores encontrados para ácidos orgânicos nas silagens de maniçoba com ou sem adição de fubá de milho mostram que houve fermentação adequada (Tabela 3). Isso pode ser confirmado através dos níveis satisfatórios de ácido láctico encontrado, indicando a presença de carboidratos solúveis, principalmente açúcares, os quais são substratos para as bactérias lácticas responsáveis pela produção deste composto orgânico. Conforme Carvalho et al. (2008), os carboidratos solúveis são utilizados durante $\mathrm{o}$ processo fermentativo para redução do pH e produção de ácido láctico, sendo que a presença desses compostos orgânicos na silagem indica a presença de açúcar residual o qual é uma fonte de energia prontamente disponível para o animal. Possenti et al. (2005), afirmam que quanto maior o ácido láctico menor a perda por proteólise, isto é, menor o teor de $\mathrm{N}-\mathrm{NH}_{3} / \mathrm{NT}$. Isso é confirmado no presente trabalho em que $\mathrm{o}$ tratamento com silagem de maniçoba sem aditivo, mesmo não apresentando diferença estatística para os demais tratamentos, apresentou o maior valor de ácido láctico e o menor em $\mathrm{N}$ $\mathrm{NH}_{3} / \mathrm{NT}$.

Tabela 3. Ácidos orgânicos em silagens de maniçoba com ou sem fubá de milho como aditivo

\begin{tabular}{lccccc}
\hline \multirow{2}{*}{ Ácidos orgânicos } & \multicolumn{4}{c}{ Níveis de aditivo $^{1}$} & \multirow{2}{*}{ CV (\%) } \\
\cline { 2 - 5 } & 0 & 10 & 20 & 30 & \\
\hline Láctico & 4,20 & 4,10 & 3,80 & 4,05 & 15,5 \\
Acético & $0,19^{\mathrm{a}}$ & $0,17^{\mathrm{ab}}$ & $0,11^{\mathrm{b}}$ & $0,10^{\mathrm{b}}$ & 17,7 \\
Propiônico & 0,05 & 0,07 & 0,09 & 0,08 & 10,3 \\
Butírico & $0,45^{\mathrm{a}}$ & $0,05^{\mathrm{b}}$ & $0,00^{\mathrm{c}}$ & $0,00^{\mathrm{c}}$ & 22,5 \\
\hline
\end{tabular}

Médias seguidas de letras diferentes na linha diferem pelo teste "Dunnett" a 5\% de probabilidade.

${ }^{1}$ Expresso em percentagem da matéria seca.

$\mathrm{CV}=$ coeficiente de variação.

A concentração de ácido acético foi significativamente reduzida $(\mathrm{p}<0,05)$ a partir da inclusão de fubá de milho, porém não houve diferença $(p>0,05)$ entre os níveis de inclusão. Isso aconteceu, provavelmente, devido a ocorrência de uma melhor compactação do material à medida que adicionou-se fubá de milho, ou seja, houve maior eliminação do oxigênio do meio o qual é responsável por um ambiente favorável para o desenvolvimento de microrganismos produtores de ácido acético, principalmente na fase inicial da fermentação da silagem. Essa observação é corroborada por Coan et al. (2005), o qual afirma que as enterobactérias são responsáveis pela 
elevada produção de ácido acético nos estádios iniciais da fermentação da silagem.

Não foi encontrada diferença entre os tratamentos $(\mathrm{p}>0,05)$ para ácido propiônico, talvez pelo fato de que o $\mathrm{pH}$ das silagens se manteve baixo (média de 4,2) e sem diferença significativa $(\mathrm{p}>0,05)$ entre os tratamentos. Segundo Ávila et al. (2010), a produção de ácido propiônico é altamente sensível ao baixo $\mathrm{pH}$, isto é, em $\mathrm{pH}$ próximo de 4,0 não há grande desenvolvimento de bactérias produtoras deste ácido. Portanto, os baixos teores de ácido propiônico encontrado nesse trabalho pode ter sido, indiretamente, ocasionado pelo baixo $\mathrm{pH}$, encontrado em todos os tratamentos.

A redução do teor de umidade com a adição do fubá de milho possivelmente reduziu as condições favoráveis para o desenvolvimento dos microrganismos clostridium, os quais são responsáveis pela fermentação butírica. Dessa forma, observou-se uma queda acentuada $(\mathrm{p}<0,05)$ nos níveis de ácido butírico com a adição do fubá de milho, chegando ao desaparecimento desse ácido orgânico em níveis de 20 e $30 \%$ de adição do aditivo. Segundo Woolford (1984), a menor atividade das bactérias Clostridium ocorrem em silagens com maior concentração de matéria seca. Esse mesmo autor preconiza níveis inferior a $0,2 \%$ de ácido butírico, na matéria seca, para que as silagens possam ser consideradas como de boa qualidade. Sendo assim, as concentrações encontradas no presente trabalho para ácido butírico, em silagens com aditivos, encontram-se dentro da faixa recomendada.

Os CHOT observados nos tratamentos envolvendo diferentes níveis de adição de fubá de milho mantiveram-se praticamente inalterados $(\mathrm{P}>0,05)$, independente das proporções adicionadas (Tabela 4). A adição de fubá de milho aumentou significativamente $(\mathrm{P}<0,05)$ os níveis de CNF. Isso já era esperado visto que o fubá de milho é extremamente pobre em CF (carboidratos fibrosos) e ricos em CNF. Costa et al. (2008) trabalhando com silagem de maniçoba sem aditivo encontraram valores de CNF de 19,23\%, inferior aos valores encontrados no presente trabalho, talvez pelo fato dos referidos autores se utilizarem de ramos mais grosseiro (maior diâmetro) do que o utilizado no presente trabalho. Já Dantas et al. (2008), ao analisar a composição química da silagem de maniçoba sem aditivo, encontraram um valor de 35,02 $\%$ para $\mathrm{CNF}$, valor esse próximo aos que aqui foram encontrados para silagem de maniçoba com aditivo.

Tabela 4. Componentes da fibra da silagem de maniçoba com diferentes níveis de fubá de milho como aditivo

\begin{tabular}{lccccc}
\hline \multirow{2}{*}{ Componentes } & \multicolumn{5}{c}{ Níveis de aditivo $^{1}$} \\
\cline { 2 - 6 } & 0 & 10 & 20 & 30 & CV \\
\hline Carboidratos totais $^{1}$ & 78,7 & 77,8 & 77,3 & 78,9 & 2,0 \\
Carboidratos não fibrosos $^{1}$ & $26,1^{\mathrm{c}}$ & $37,5^{\mathrm{b}}$ & $43,9^{\mathrm{a}}$ & $38,3^{\mathrm{b}}$ & 7,1 \\
Fibra em detergente neutra $^{1}$ & $52,6^{\mathrm{a}}$ & $40,2^{\mathrm{b}}$ & $33,3^{\mathrm{c}}$ & $40,5^{\mathrm{b}}$ & 4,9 \\
Fibra em detergente ácida $^{1}$ & $46,9^{\mathrm{a}}$ & $35,6^{\mathrm{b}}$ & $29,6^{\mathrm{c}}$ & $33,8^{\mathrm{bc}}$ & 6,1 \\
Celulose $^{1}$ & $28,6^{\mathrm{a}}$ & $22,4^{\mathrm{b}}$ & $18,0^{\mathrm{c}}$ & $21,7^{\mathrm{b}}$ & 7,2 \\
Hemicelulose $^{1}$ & 5,7 & 4,6 & $7,9^{\mathrm{a}}$ & 6,7 & 6,1 \\
Lignina $^{1}$ & $18,2^{\mathrm{a}}$ & $13,2^{\mathrm{b}}$ & $11,5^{\mathrm{b}}$ & $12,1^{\mathrm{b}}$ & 5,9 \\
\hline
\end{tabular}

Médias seguidas de letras diferentes na linha diferem pelo teste "Dunnett" a 5\% de probabilidade.

${ }^{1}$ Expresso em percentagem da matéria seca. 
Com relação aos teores de FDN e FDA houve decréscimo significativo $(\mathrm{p}<0,05)$ com a inclusão do fubá de milho, sendo encontrado o menor valor para o tratamento com $20 \%$ de aditivo. Isso mostra que a inclusão do fubá de milho melhorou a fermentação com conseqüente melhora na digestibilidade das frações associado ao fato de que o aditivo é pobre em fibra o que também ajudou, em termos de proporção, a diminuir o teor de FDN e FDA total. Comparando somente silagem de maniçoba sem aditivo observa-se que os valores aqui encontrados para FDN $(52,6$ 5) e FDA (46,9 \%) foram superiores aos valores encontrados por Costa et al. (2008) e por Dantas et al. (2008) os quais foram de 50,2 \% e 36,4 $\%$ e de $42,58 \quad \%$ e $38,09 \%$, respectivamente.

Para CEL e LIG observa-se que houve queda significativa $(\mathrm{p}<0,05)$ nesses valores com a adição de fubá de milho como aditivo. Isso provavelmente aconteceu devido à uma melhor fermentação (láctica) ocorrida nas silagens com aditivo o que provocou uma melhora na digestibilidade colaborando para que houvesse redução nos valores de CEL e, principalmente, nos níveis de LIG, associado ao fato de que o fubá de milho é pobre em celulose e lignina o que acabou por colaborar também na redução destes componentes na silagem. Os valores de LIG encontrados no presente trabalho para silagem de maniçoba foram superiores aos valores encontrados em literaturas (COSTA et al, 2008; DANTAS et al, 2008; MEDINA et al, 2009).

A silagem de maniçoba mostra-se uma alternativa alimentar de bom valor nutricional, principalmente quando adicionado de fubá de milho como aditivo. $\mathrm{O}$ melhor nível de inclusão de fubá de milho na silagem da maniçoba é de $20 \%$.

\section{REFERÊNCIAS}

ANDRADE, A.P.; QUADROS, D.G.; BEZERRA, A.R.G.; ALMEIDA, J.A.R.; SILVA, P.H.S.; ARAÚJO, J.A.M. Qualitative aspects of elephantgrass silage with corn meal and soybean hulls. Semina: Ciências

Agrárias, v.33, n.3, p.1209-1218, 2012.

ARAÚJO, M.J.; MEDEIROS, A.N.; CARVALHO, F.F.R.; SILVA, D.S.; CHAGAS, E.C.O. Intake and digestibility of nutrients in Moxotó dairy goats fed diets with different Maniçoba hay levels. Revista Brasileira de Zootecnia, v.38, n.6, p.1088-1095, 2009.

ÁVILA, C.L.S.; VALERIANO, A.R.; PINTO, J.C.; FIGUEIREDO, H.C.P.; REZENDE, A.V.; SCHWAN, R.F. Chemical and microbiological characteristics of sugar cane silages treated with microbial inoculants.

Revista Brasileira de Zootecnia, v.39, n. 1, p.25-32, 2010.

CAPELLE, E.R.; VALADARES FILHO, S.C.; COELHO DA SILVA, J.F. CECON, P.R. Estimates of the Energy Value from Chemical Characteristics of the Feedstuffs.

Revista Brasileira de Zootecnia, v.6, n.30, p.1837-1856, 2001.

CARVALHO, G.G.P.; GARCIA, R.; PIRES, A.J.P.; PEREIRA, O.G.; FERNANDES, F.E.P.; CARVALHO, B.M.A. Fermentation characteristics of silage of elephantgrass wilted or with addition of cocoa meal. Arquivo

Brasileiro de Medicina Veterinária e Zootecnia, v.60, n.1, p.234-242, 2008. 
COAN, R.M.; VIEIRA, P.F.;

SILVEIRA, R.N.; REIS, R.A.; MALHEIROS, E.B.; PEDREIRA, M.S. Enzymatic-bacterial inoculants, chemical composition and fermentation characteristics of Tanzaniagrass and Mombaçagrass silages. Revista Brasileira de Zootecnia, v.34, n.2, p.416-424, 2005.

COSTA, R.G.; MESQUITA, I.V.U.; QUEIROGA, R.C.R.E.; MEDEIROS, A.N.; CARVALHO, F.F.R.; FILHO, E.M.B. Sensorial and chemical characteristics of the milk of Moxotó goats fed with maniçoba silage. Revista Brasileira de Zootecnia, v.37, n.4, p.694-702, 2008.

DANTAS, F.R.; ARAÚJO, G.G.L.; SILVA, D.S.; PEREIRA, L.G.R.; NETO, S.G.; TOSTO, MS.L. Chemical composition and fermentation characteristic in cassava ("Manihot" sp.) silages with different proportion of grape wine residue. Revista Brasileira de Saúde e Produção Animal [online], v.9, n.2, p.247-257, 2008.

GUIM, A.; FILHO, E.C.P.; SOUSA, M.F.; SILVA, M.M.C. Fermentation pattern and chemical composition of fresh and wilted Ipomoea glabra choisy and Jaquemontia asarifolia L.B. Smith silages. Revista Brasileira de

Zootecnia, v.33, n.6, p.2214-2223, 2004.

MATHEW, S.; SAGATHEVAN, S.; THOMAS, J.; MATHEN, G. An HPLC method for estimation of volatile fatty acids in ruminal fluid. Indian Journal of Animal Science, v.67, n.9, p.805807, 1997.
MATOS, D.S.de.; GUIM, A.; BATISTA, A.M.V.; PEREIRA, O.G.; MARTINS, V. Chemical composition and nutritional value of the maniçoba silage (Manihot Epruinosa). Archivo de Zootecnia, v.54, p.619-629, 2005.

MEDINA, F.T.; CÂNDIDO, M.J.D.; ARAÚJO, G.G.L.; BARROSO, D.D.; CRUZ, M.C.S. Manioc silage associated with different energy sources in goat feeding: performance. Acta Scientiarum Animal Sciences, v.31, n.2, p.151-154, 2009.

PINHO, E.Z.; COSTA, C.; ARRIGONI, M.D.B.; SILVEIRA, A.C.;

PADOVANI, C.R.; PINHO, S.Z.

Fermentation and nutritive value of silage and hay made from the aerial part of cassava (Manihot esculenta Crantz). Science Agriculture, v.61, n.4, p.364370, 2004.

PLAYNE, M.J.; McDONALD, P. The buffering constituents of herbage and of silage. Journal of the Science of Food and Agriculture, v 17, p.264-268, 1966.

POSSENTI, R.A.; FERRARI JUNIOR, E.; BUENO, M.S.; BIANCHINI, D.; LEINZ, F.F.; RODRIGUES, C.F. Bromatological and fermentative parameters of corn and sunflower silages. Ciência Rural, v.35, n.5, p.1185-1189, 2005.

SILVA, D.S.; CASTRO, J.M.C.; MEDEIROS, A.N.; FILHO, E.C.P.; BARROSO, D.D. Maniçoba hay in diets for sheep: intake, apparent digestibility and nitrogen balance.

Revista Brasileira de Zootecnia, v.36, n.5, p.1685-1690, 2007. Supl. 
Rev. Bras. Saúde Prod. Anim., Salvador, v.15, n.1, p.182-191 jan./mar., 2014 http://www.rbspa.ufba.br ISSN 15199940

SILVA, D.J.; QUEIROZ, A.C. Análises de alimentos: métodos químicos e biológicos. 2.ed. Viçosa:UFV, 2002. $235 \mathrm{p}$.

SNIFFEN, C.J.; O CONNOR, J.D.; VAN SOEST, P.S.; FOX, D.G.; RUSSELL, J.B. A net carbohydrate and protein system for evaluating cattle diets: II. Carbohydrate and protein avallability. Journal Animal Science, v.70, n.11, p.3562-3577, 1992.

STATISTICAL ANALYSIS SYSTEMS. User's guide: Stat.

Version 9. Cary: SAS Institute, 2004.

WOOLFORD, M.K. The silage

fermentation. New York: Marcel Dekker, 1984. 350p.

Data de recebimento: $12 / 08 / 2013$

Data de aprovação: 24/03/2014 